\title{
What Can the Philippines Learn from Thailand's ENCON Fund in Overcoming the Barriers to Developing Renewable Energy Resources
}

\author{
Phoebe Grace J. Saculsan and Akihisa Mori
}

\begin{abstract}
Energy security and climate strategy are the twin goals behind the aggressive promotion of Philippines and Thailand for developing renewable energy (RE) resources. Investment in the RE sector in the Philippines, however, has been weigh down by barriers including: (i) the difficulty in accessing finance; the (ii) tedious administrative procedures; and (iii) the lack of local acceptance, as identified from documentary reviews and in the survey interview done in the Philippines in 2016. The author explores in this paper the design and the mechanism of the Energy Conservation (ENCON) Fund, a well-acclaimed innovative financing scheme which is said to be a key that makes Thailand an investment hub for clean energy investment, from which the Philippines can learn from to similarly address these barriers to its own RE goals.
\end{abstract}

Index Terms-Barriers to RE development, ENCON fund, renewable energy sector, Philippines, Thailand.

\section{INTRODUCTION}

The energy sector is one of the priority areas for development that both Philippines and Thailand are currently actively pursuing. It is because a growing economy and population will accompany a huge demand for energy. For these countries that are dependent on imported conventional energies (i.e., coal, natural gas, and oil), attaining energy security while maintaining its climate change commitment have made renewable energy (RE) a 'win-win` choice. This the reason why Thailand and Philippines have become frontrunners in the ASEAN region in developing RE technologies by adopting it to a wider, broader scope as increased in the respective country`s energy mix.

In 1978, the Philippines began to utilize its own geothermal resources through the 'Act to Promote the Exploration and Development of Geothermal Resources` [1] which placed the Philippines on top for geothermal development. This initiative was followed by several policies to promote clean energy. The year 2008 was a milestone when the Philippines, the first in ASEAN, passed the Renewable Energy Law (or Republic Act 9513) which breathed life into the National Renewable Energy Plan (NREP) in 2011 [2]. This law is to complement the Philippine Energy Plan 2012-2030 which considers renewable energy (RE) as a strategy for the country to achieve the following: (i)

Manuscript received August 24, 2018; revised July 12, 2018. This work was supported in part by the Education Unit for Studies on the Connectivity of Hills, Humans, and Oceans (CoHHO) FY 2016, Kyoto University, Japan.

P. G Saculsan is with the Graduate School of Global Environmental Studies (GSGES), Yoshida-Honmachi, Sakyo-ku, Kyoto, 606-8501, Japan (email: pjsaculsan@gmail.com). energy supply security; (ii) reduce dependence on imported oil; and (iii) reverse the adverse effects of energy uses to the environment.

Thailand`s renewable energy program, on the other hand, was embedded under the country`s comprehensive energy framework, the Thailand Integrated Energy Blueprint ("TIEB") which includes the following: 1) the Alternative Energy Development Plan ("AEDP"); 2) the Power Development Plan 2015-2036 ("PDP"); the 3) the Energy Efficiency Plan 2015-2036 ("EEP"); the 4) Gas Plan; and the 5) Oil Plan [3].

Before this, Thailand's 'Strategic Plan for Renewable Energy Development' that was established in 2004 was considered to be the 'earliest most comprehensive strategic development plans, with a multi-sector focus and multi-policy components' in the ASEAN region [1].

Following the policy framework for RE development on these countries, incentives were established (as shown in Table I). When compared among ASEAN countries, the Philippine is shown to provide one of the most comprehensive RE incentive package and the highest offered FIT rates. FIT is a guaranteed payment for every $\mathrm{KwH}$ of energy that comes from RE sources.

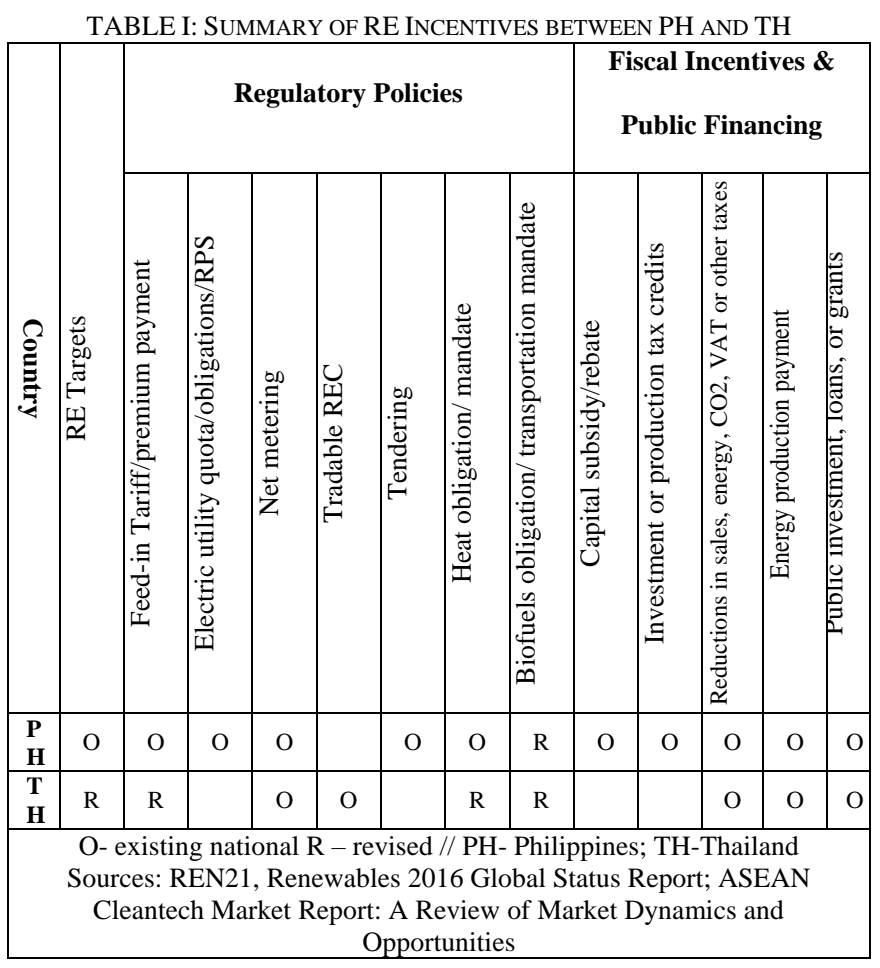

With the establishment of policy framework for the development of RE and the incentives given to attract 
investment in the sector, the author looks into the achievements of the RE sector between Philippines and Thailand in terms of i) increased shares of RE in the energy mix and the ii) amount of investments.

By looking into each country's energy mix, Philippines fared well having larger share of RE although growth has been stagnant over the years. Thailand, on the hand, has had a modest growth of RE share in its energy portfolio alongside increasing energy demand (See Fig. 1 and 2). The Philippines goals to increase to 40 percent its RE share by 2020 while Thailand targets a share of 25 percent by 2021 . This can be problematic given that, at present, already a large portion of these TPES of both countries are imported conventional energies. For Philippines alone, this consists about 70 percent due to its sparse domestic supply.

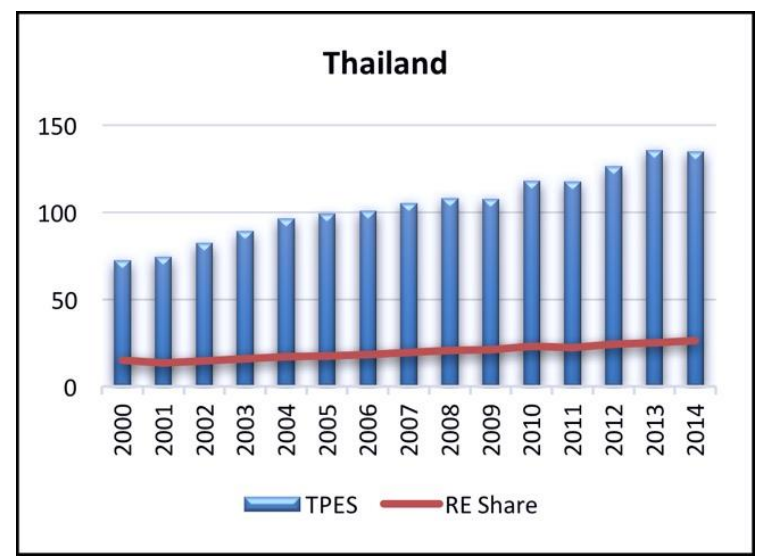

Fig. 1. Thailand's RE Share, 2000-2014.

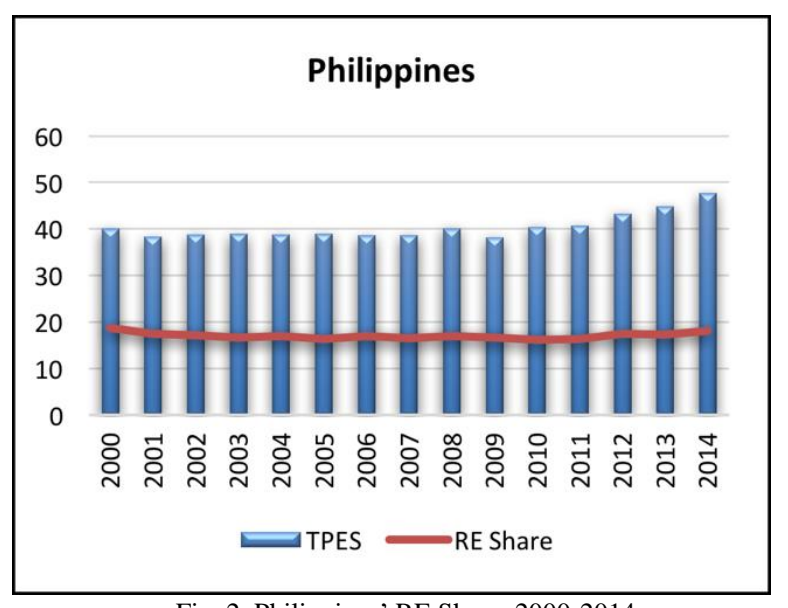

Source: OECD Energy Data

In terms of investments in clean energy, Thailand performs ahead not only among ASEAN countries but all emerging economies. Over the five-year period from 2009-2013, Thailand attracted USD 5.6 Billion of clean energy investments compared to only USD 1.9 Billion in the Philippines (ranked $10^{\text {th }}$ ) [4].

As both countries are still struggling to achieve their clean energy targets, it is likewise important to discuss the ways and means for which these emerging economies have addressed where they are lacking in approach in developing their respective RE sector, for example. This paper takes Philippines as a starting point by looking into the challenges that its RE sector faces - a scenario that is also common among countries in the ASEAN region.

\section{The Challenges IN THE PhiLipPine RenEWABLE ENERGY DEVELOPMENT}

Initially, DOE has been implementing a "first come first served" policy, wherein an RE developer, after submitting necessary documentary requirements, can be qualified for the FIT incentive. In 2013, under the leadership of then Energy Secretary Jericho Petilla, DOE revised its "first come first serve" policy to a default "first come first to commercialize" [5]. That is, to be eligible for the FIT incentive, an RE project must attain a "status of commerciality" that essentially means it must build the facility and pass the criteria first before it can qualify for the FIT incentive [5]. This is a strategy meant to weed out speculators and retain those who are serious about in developing their proposed RE projects.

The pitfall of the new approach, however, is that it gives the big energy players the undue advantage because they already have the experience and the capital to build an RE project.

Moreover, RE installation has long been made difficult by the complex permitting process with too many agencies involved, while sometimes requiring redundant (if not conflicting) documents that affords time and additional costs for the RE developers. A study published by the German development agency [6], for example, has shown that building a $3-\mathrm{KwH}$ retrofit solar project in the Philippines entails about $\mathrm{PhP} 56,840$, which is equivalent to $11 \%$ of total project cost, and 28 man-days to complete the application. In reality, this could take months and more costs especially for other types of renewables that is more burdened with the land and licensing permits. Such is the case when one has to deal with the LGUs (Local Government Units) and the IPs (Indigenous Peoples), which all respondents have identified to take most of their time and is a strenuous work. In fact, it takes them at least a year just to overcome these needed approvals and permits from the local level [7]. That is, without an open mindset about the multitude benefits of RE to a community, permitting and licensing will remain to be a challenge for RE developers in the Philippines.

The case presented above is just one of the many ways in which an RE project can be stalled or delayed in the Philippines.

In summary, the result of a comprehensive documentary review and as verified through a survey interview in the Philippines in 2016 had these three main barriers identified: i) difficulty in accessing finance; ii) tedious permit and licensing process; and lastly iii) the lack of local acceptance. Equally so, these are the barriers experience in Thailand from which the creation of the ENCON program viz. the ENCON Fund was aimed at.

\section{WHAT IS THAILAND'S ENCON FUND?}

The Energy Conservation (ENCON) Program was established under the virtue of the Energy Conservation Promotion Act of 1992. The ENCON Fund was the funds allocated to run this program. The ENCON Program was established in order to accomplish specific objectives and targets for energy conservation, which is underlined in these three (3) major sub-areas:

1. A compulsory program for large energy users (Designated Facilities), which comprise approximately 4,500 large commercial and 
industrial facilities (buildings and factories)

2. A voluntary program that applies to smaller facilities, primarily targeting small and mediumsized enterprises (SMEs), and covers a range of activities such as research, development and demonstration, information campaigns, and other special projects.

3. Establishment of the Energy Conservation Promotion Fund (ECON Fund): The main objective of the Energy Conservation Promotion Fund (ENCON Fund) is to provide financial support to designated factories and buildings for investment in and operations of energy conservation programs. At the same time, the ENCON Fund can also be used to support other agencies that wish to undertake energy conservation, including RE projects, energy-related research and development, human resource development and training, and public awareness campaigns. The Fund is financed by a tax on petroleum products (THB 0.04/USD 0.001 per litre) with approx. USD 200 million per year since 1992.

(Source: Definition taken from Frankfurt School - UNEP (2012), Case Study: The Energy Efficiency Revolving Fund)

The Department of Alternative Energy Development and Efficiency (DEDE) is the governing body that manages the Compulsory Programs and is more focused on energy conservation activities. On the other hand, the National Energy Policy Office (NEPO), later replaced by the Energy Policy and Planning Office (EPPO), oversees the Voluntary and other Complementary Programs and formulates strategic policies for both energy conservation and renewable energy [8].

The ENCON Program is divided into several, different phases, currently at Phase IV, and are tied up to specific objectives and accorded a budget. Since its inception in 1995, the ENCON Program has disbursed at least THB 78.8 billion (around USD 2.2 billion based on 23 January 2017 exchange rate) in total. Annually, around THB 7,000 million (USD 200 million) is made available for use through the so-called ENCON Fund, which is primarily sourced from the tax revenues on petroleum products (gasoline, diesel, fuel oil and kerosene) [9].

Phase I and Phase were assessed to deliver energy savings of a total THB `13,489.5 million/year while Phase III and Phase IV have targets of increasing RE share to final energy demand of $15.6 \%$ and $25 \%$ respectively [10], [11].

Although the ENCON Program was highly successful in its objectives, it is not without its own flaws. During the beginning of the program, there was a huge backlog on project approvals caused by administrative procedures, excessive reporting requirements, and non-compliance, among others. The government is still trying to further streamline the process. It tapped the private sector and civic organizations to assist in improving the mechanism.

\section{THE DESIGN AND MECHANISM OF THE ENCON FUND THAT ADDRESS BARRIERS TO DEVELOPING RENEWABLE ENERGY RESOURCES}

This section will discuss the elements of the ENCON
Program that can address barriers in RE sector development in the Philippines, as identified in the previous section.

\section{A. Difficulty in Accessing Finance}

Each phase of the ENCON Program is designed in a way to achieve well-defined objectives and address specific concerns that limit progress in energy conservation and investments in RE. Beginning in the Phase II of the ENCON Program, it became the priority of the government "to increase market mechanism and to gradually reduce financial assistance from the ENCON Fund". Thus, to stimulate private sector engagement into clean energy initiatives, two (2) sub-programs were established after: The Energy Efficiency Revolving (EER) Fund and the Energy Service Company (ESCO) Fund.

The EER Fund (or more commonly known as "Revolving Fund") was launched in 2003 to assist project developers access debt financing for their EE and RE projects, typically costing above USD 100,000, through channeling funds to participating local banks [12,13]. These banks would offer low-interest loan rate, at fixed rate between 0 to 4 percent lower than the ongoing market rate of 9 percent $[12,13]$. The loan can finance the whole project cost of up to THB 50 million (USD 1.4 million) and is payable within a seven-year loan period [12]. The revenue that is collected from the loan payments will be returned to the EER Fund to be lent again, thus, the term "revolving".

Similarly, the ESCO Fund is created in 2008 but this time it is more focused in encouraging participation of the small-to-medium enterprises (SMEs). Under the ESCO Fund, an investor/developer may choose among six (6) funding assistance instruments: equity, venture capital, equipment leasing, partial credit guarantees, carbon credit rating, and technical assistance [12].

In terms of financing the ENCON Fund, as stipulated in the ENCON Act, these may come from the following sources: i) surcharges for use of electricity (collected from designated factories/buildings that violate or fail to comply with Ministerial Regulations); ii) subsidies from the government; iii) money or property received from the private sector, local or abroad; and iv) interests and benefits incurred from the ENCON Fund [14]. Up to this date, however, none of the aforementioned potential sources has contributed to the ENCON Fund. All of the funds come from tax levies on petroleum products.

The funding mechanism of the ENCON Fund works around the "polluters pay principle" and is successful in directly linking the "penalties" derived from the "pollutants" to fund environmentally friendly initiatives, particularly in the energy sector. Also, since the funds do not come from the taxpayers, it does not add burden to the people and is basically sustainable.

This is something that the Philippines or other emerging economies for that matter that similarly may have difficulty in sourcing funds to pursue their respective clean energy goals may to look into. Like Thailand, the Philippines has been a major fossil fuel importer. However, unlike Thailand, the Philippines does not impose taxes on its fossil fuel products beside the usual value-added tax (VAT). Until this moment, the policymakers in the Philippines are still trying to push for additional tax on fossils [15]. This continues to be a policy backlog, perhaps, given that the electricity sector is 
monopolized by companies with huge stakes on conventional energy sources. It is also worth noting that the VAT collected from fossil fuel taxes in the Philippines is not directly tied to any climate change strategies.

The government may also opt to supplement its ENCON Fund of international grants and pledges. Thailand is very successful in doing so by mobilizing "extra-budgetary funds" to finance its climate-related activities. Extra-budgetary funds in Thailand have grown sharply over the years, from THB 37 billion (USD 1 billion; 3 percent) in 2001 to THB 408 billion (USD 11 billion; 13 percent) in 2013, most of which is used to support social welfare activities [16]. These funds have been sourced mainly from donations, borrowing, compensation from government, and so on [16].

Philippine can do the same and can be said to be in a better position now after securing the highest foreign assistance of roughly around USD 1 trillion in just a short period of time during the current administration of President Rodrigo Duterte [17] because of the growing confidence of investors to the potentials of the country.

Both the EER and the ESCO Funds under the ENCON Fund became well-known models of innovative financing especially in leveraging access to finance and boosting the confidence of local banks that were previously reluctant to lend to RE and ESCO projects. This fund was also successful in directly linking "polluter's penalties" into funding clean energy targets.

\section{B. Tedious Administrative Procedures}

The EER and ESCO Funds were established after the slow progress during the initial implementation of the ENCON Fund, which is said to be a result of the tedious administrative procedures in the application, and the monitoring and evaluation process. This was addressed by granting the participating banks the "full control" on almost all aspects of the lending process, which in turn, has also helped increased these bank's technical capacity in assessing RE and EE projects [13].

The participating banks are the ones responsible for all the aspects of the lending process: from marketing, the technical/economic assessment, credit approval, loan repayment in case of default, to regular submission of reports to ensure that the approved projects are on the right track and are delivering its promised energy savings [See Figure 3; 13]. They are also responsible the loaned amount in case of default.

Moreover, the ENCON Fund provides technical assistance in assessing the loan applications by having in-house Fund Managers and consultants to manage its mechanism. Because of these, the banks became more experienced and knowable of the nature of RE and EE projects - "learn by doing" - they eventually became independent lenders leading to the sustainability of the mechanism over time [12]. For the Philippines, this is an opportunity to train banks to move to a "project-based" rather than an "asset-based" assessment.

To ensure transparency and that the objectives are achieved, DEDE maintains a database to monitor the lending bank`s performance, analyze the needs of the customers, and track the progress of the individual projects under the EER Fund [8]. One of the appointed-NGOs that manages the ESCO Fund, the Energy for Environment Foundation
(EforE), discloses information on their website [18] about the approved loan amount, company profile, and the energy reductions and savings of each project. Lastly, EPPO reports on the expense and accomplishments of the each of the phase of the ENCON Fund on their website [19].

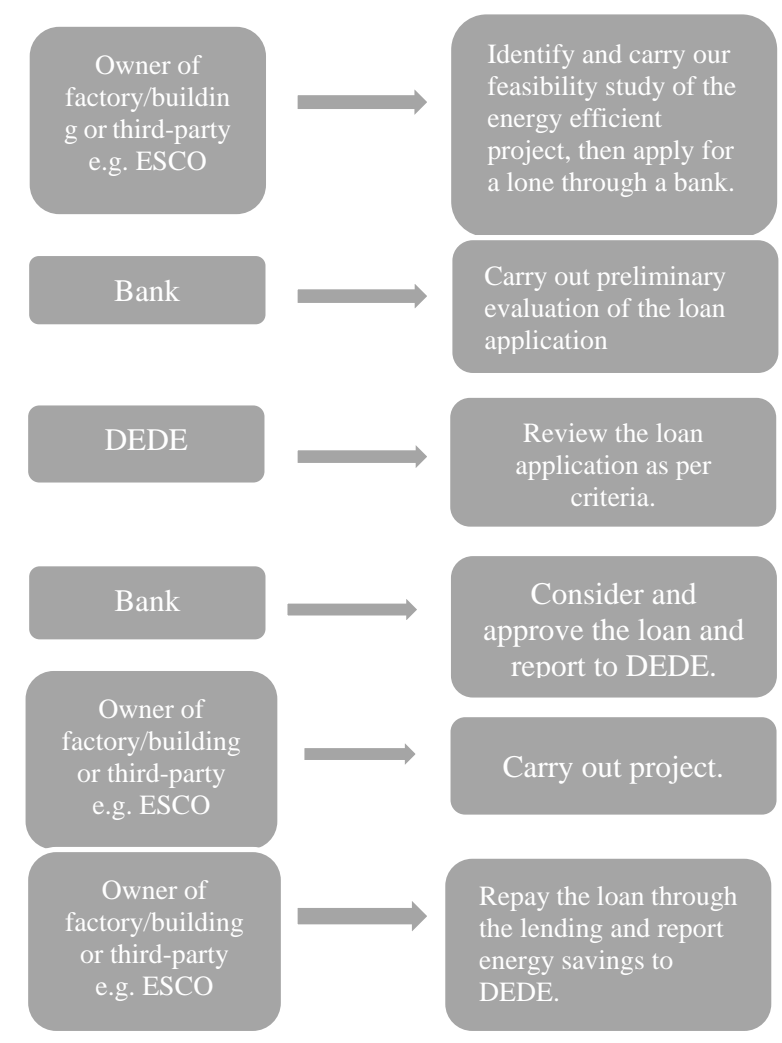

Fig. 3. EER fund lending process.

Taken from: Energy Futures Australia and the Danish Management Group (Thailand), 2005)

\section{Lack of Local Acceptance}

Each phase of the ENCON Fund has identified target groups. This is to ensure that "everyone" is on board to achieving energy conservation goals, but through gradual inclusion. The ENCON Fund - Phase I, for example, has government buildings/facilities as the target group in order to make them "models" of energy conservation before expanding the program to include other sectors [11].

Tailored-fit strategies have been used to approach the different target groups. When the private sector engagement became the priority objective of ENCON Fund - Phase II, access to finance was identified to be one of the main barriers, thus, EER and ESCO Funds were correspondingly established to address the issue. EER Fund mostly caters to the large companies whereby ESCO Fund is more focused on the small and medium enterprises (SMEs).

The ENCON Fund has also emphasized the need in utilizing the RE resources in the rural and agricultural communities by providing subsidies and by building demonstration projects. The biogas system in swine farms is one good example. As of December 2013, there are about 1,568 biogas plants that were installed under the ENCON Fund [20]. This mechanism has helped introduced the benefits of RE to the local community. Since they directly benefit from these RE installations, they become more open 
and accepting - something that needs to be done in the Philippines as one of the main barriers for establishing an RE facility in certain areas is the difficulty in getting land permits due to local oppositions [7].

\section{LIMITATIONS AND FUTURE RESEARCH}

This paper discusses the three (3) main barriers in developing RE resources in emerging economies taking Philippines and Thailand as cases. This time, the paper has focused on RE and not on energy efficiency initiatives yet. Energy efficiency is another topic that needs attention and for which the ENCON Fund is also relevant. The paper has also not touched on the constitutional process and policy mechanism to make a similar ENCON program viz. ENCON Fund a reality in the Philippines. Lawmakers in the Philippines are now in the process of discussing constitutional change to make way for a federalist type of government. Federalism is a policy agenda being pushed by the Philippine president himself. From the author's point of view, this may open a pleasant opportunity for the RE sector to have a bottom-up, inclusive and community-based approach to RE, a formula that was crucial in the successful implementation of the RE program in The Netherlands. This is another topic that the author wishes to explore for future research.

\section{SUMmARY AND CONCLUSIONS}

The goal to attain energy security and climate strategy are the two driving forces behind the Philippines and Thailand`s aggressive promotion of clean energy. In order to attain their respective energy targets, Philippines and Thailand have established incentive mechanisms to increase the private sector engagement. However, the Philippine RE sector has been weigh down by barriers such as: (i) difficulty in accessing finance; the (ii) tedious administrative procedures; and the (ii) lack of local acceptance, as identified from documentary reviews and in the survey interview done in the Philippines in 2016. Furthermore, the new "first come first to commercialize" policy requires that projects be built and passed the criteria before they can be qualified for the Feed-in Tariff (FIT) incentive. This has consequently given undue advantage to the big energy players that already have the experience and the own capital to build their projects.

The Energy Conservation (ENCON) Fund of Thailand is a well-acclaimed model of innovative financing. The ENCON Fund is sourced from tax levies on petroleum products and is directly tied in financing clean energy initiatives. Under the ENCON Fund, two financing schemes, the Energy Efficiency (EER or "Revolving") Fund for large industries and the Energy Service Company (ESCO) Fund for small and medium enterprises (SMEs) were established to specifically increase the private sector engagement. EER and ESCO channel funds to participating local banks to lend at a low interest rate (maximum 4\%) and by giving them technical assistance. Also, the banks were allowed to manage the whole lending process and the duty to pay the loaned amount in case of default. This has provided knowledge and experience to the banks, which enabled them to lend without

\section{the ENCON Fund over time.}

To ensure the scheme's transparency, on the other hand, the government and two appointed NGOs regularly publishes reports on their respective websites.

Because of the initiatives under the ENCON program, Thailand became the leading emerging economy to attract the most investments into clean energy. Analyzing the design and the mechanism of the ENCON program viz. the ENCON Fund has provided insights and learnings for the Philippines to help it address and overcome the barriers in developing its RE resources.

\section{ACKNOWLEDGMENT}

The author wishes to acknowledge the support and guidance of her supervisor, Professor Akihisa Mori of Kyoto University; and the valuable comments of Laurence Delina, $\mathrm{PhD}$; and Sopitsuda Tongsopit, PhD of Energy Research Institute, Chulalongkorn University that help to improve the contents of this paper.

\section{REFERENCES}

[1] C. Dent, Renewable Energy in East Asia: Towards a New Developmentalism, New York: Routledge, 2014.

[2] PDO Energy, Philippine Energy Plan 2012-2013, Philippine Department of Energy, Taguig City: Department of Energy, 2014

[3] Lorenz \& Partners, Renewable Energy in Thailand, Bangkok: Lorenz \& Partners, 2016.

[4] The Pew Charitable Trusts, Power Shifts: Emerging Clean Energy Markets, The Pew Charitable Trusts, 2015.

[5] A. R. Remo, "First come, first served policy for RE projects," Philippine Inquirer, February 12, 2013

[6] R. Burckmann, Administrative Procedures Rules and Processes for On-Grid PV Project Development in the Philippines, Berlin: Deutsche Gesellschaft für Internationale Zusammenarbeit (GIZ) GmbH, 2013.

[7] Anonymous, Renewable Investments and Financing in the Philippines, (P. G. Saculsan, Interviewer), September 15, 2016.

[8] Energy Futures Australia and the Danish Management Group (Thailand), Thailand's Energy Efficiency Revolving Fund: A Case Study, Bangkok: Energy Futures Australia and the Danish Management Group (Thailand), 2005.

[9] X. D. Wang and R. Stern, "Case study: Thailand energy conservation (ENCON) fund," in Unlocking Commercial Financing for Clean Energy in East Asia, R. Stern and X. Wang ed., Washington: The World Bank, pp. 219-226, 2013.

[10] A. B. Chaisinboon, Case Study: Thailand Energy Efficiency Development Plan, Bangkok: United Nations Economic and Social Commission for Asia and the Pacific.

[11] Energy Policy and Planning Office (January 23, 2017). Energy conservation promotion (ENCON) fund. Energy Policy and Planning Office $\quad$ (EEPO). [Online]. Available: http://www2.eppo.go.th/encon/encon-fund07.html

[12] E. Jue, et al., Case Study: Thailands Energy Conservation (ENCON) Fund: How Financial Mechanisms Catalyzed Energy Efficiency and Renewable Energy Investments, Washington: Center for Clean Air Policy (CCAP).

[13] S. Vongsoasup, et al., Piloting the Way to a More Effective Energy Strategy: Thailand's Simplified Subsidy and Finance Initiatives, American Council for an Energy-Efficient Economy, 2002.

[14] S. Irawan and A. Heikens, Case Study Report: Thailand Energy Conservation Fund, United Nations Development Programme (UNDP), 2012

[15] C. F. Herrera, "VAT increase to $15 \%$ looms: Cabinet also pushes for oil tax hike," The Manila Standard, August 15, 2016.

[16] W. Suanin, Growth-Government Spending Nexus: The Evidence of Thailand, Bangkok: Thammasat University.

[17] Philippine News Agency, "Duterte secures highest foreign assistance at 1-T in short period," The Manila Bulletin, January 15, 2017.

[18] Energy for Environment Foundation (EforE). [Online]. Available: "http://www.efe.or.th" http://www.efe.or.th

[19] [19] Energy Policy and Planning Office (EPPO). [Online]. Available: "http://www2.eppo.go.th" http://www2.eppo.go.th

[20] GIZ, Policy Briefing Thailand: Biogas, 2014. 


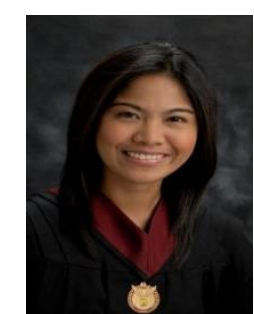

Phoebe Grace J. Saculsan graduated from the Graduate School of Global Environmental Studies (GSGES), Kyoto University, Japan. Her research interests include: energy policy, investment and financing in renewable energy, and data modelling and analysis. She came to Japan after receiving a full scholarship under the Japanese Government Scholarship (Monbukagakusho) in 2015
For her bachelors, Ms. Saculsan received her BS Economics from the University of the Philippines (UP), graduated cum laude in 2011. After graduation, she immediately took graduate courses in Philosophy in the same university in 2011-2014.

She worked as a researcher for the Third World Research Center, UP; the Ateneo de Manila University School of Government; and the USAID-Philippines before coming to Japan. 